Peter J. Hutchinson Ibrahim Jalloh $(1)$ Adel Helmy

Keri L. H. Carpenter Elham Rostami Bo-Michael Bellander Martyn G. Boutelle Jeff W. Chen Jan Claassen Claire Dahyot-Fizelier Per Enblad Clare N. Gallagher Raimund Helbok Lars Hillered Peter D. Le Roux Sandra Magnoni Halinder S. Mangat David K. Menon Carl-Henrik Nordström Kristine H. O'Phelan Mauro Oddo Jon Perez Barcena Claudia Robertson Elisabeth Ronne-Engström Juan Sahuquillo Martin Smith Nino Stocchetti Antonio Belli T. Adrian Carpenter Jonathan P. Coles Marek Czosnyka Nil Dizdar J. Clay Goodman Arun K. Gupta Troels H. Nielsen Niklas Marklund Ambroise Montcriol Mark T. O'Connell Maria A. Poca Asita Sarrafzadeh Richard J. Shannon Jane Skjøth-Rasmussen Peter Smielewski John F. Stover Ivan Timofeev Paul Vespa Elizabeth Zavala Urban Ungerstedt

\section{Consensus statement from the 2014 International Microdialysis Forum}

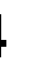


Published online: 21 July 2015

(C) The Author(s) 2015. This article is published with open access at Springerlink.com

The participants of the 2014 International Microdialysis Forum are listed in the electronic supplementary material (134_2015_3930_MOESM1_ESM).

Electronic supplementary material The online version of this article (doi:10.1007/s00134-015-3930-y) contains supplementary material, which is available to authorized users.

\section{P. J. Hutchinson (}

Division of Neurosurgery, Department of

Clinical Neurosciences, University of

Cambridge, Box 167, Cambridge

Biomedical Campus, Cambridge CB2 0QQ, UK

e-mail: pjah2@cam.ac.uk

Tel.: (+44) 1223336946

I. Jalloh · A. Helmy · K. L. H. Carpenter .

E. Rostami · B.-M. Bellander

M. G. Boutelle · J. W. Chen · J. Claassen
C. Dahyot-Fizelier · P. Enblad .

C. N. Gallagher · R. Helbok · L. Hillered •

P. D. Le Roux - S. Magnoni ·

H. S. Mangat · D. K. Menon .

C.-H. Nordström · K. H. O'Phelan ·

M. Oddo · J. Perez Barcena .

C. Robertson - E. Ronne-Engström ·

J. Sahuquillo · M. Smith · N. Stocchetti ·

A. Belli - T. A. Carpenter - J. P. Coles .

M. Czosnyka · N. Dizdar · J. C. Goodman

A. K. Gupta - T. H. Nielsen · N. Marklund ·

A. Montcriol · M. T. O'Connell .

M. A. Poca - A. Sarrafzadeh ·

R. J. Shannon - J. Skjøth-Rasmussen ·

P. Smielewski · J. F. Stover · I. Timofeev ·

P. Vespa $\cdot$ E. Zavala $\cdot$ U. Ungerstedt

Participants of the 2014 International

Microdialysis Forum, University of

Cambridge, Cambridge, UK

I. Jalloh

e-mail: ij232@cam.ac.uk

Abstract Microdialysis enables the chemistry of the extracellular interstitial space to be monitored. Use of this technique in patients with acute brain injury has increased our understanding of the pathophysiology of several acute neurological disorders. In 2004, a consensus document on the clinical application of cerebral microdialysis was published. Since then, there have been significant advances in the clinical use of microdialysis in neurocritical care. The objective of this review is to report on the International Microdialysis Forum held in Cambridge, UK, in April 2014 and to produce a revised and updated consensus statement about its clinical use including technique, data interpretation, relationship with outcome, role in guiding therapy in neurocritical care and research applications.

Keywords Brain chemistry . Microdialysis · Outcome . Subarachnoid hemorrhage . Traumatic brain injury

\section{Introduction}

Microdialysis is unique in that it allows the chemistry of the extracellular interstitial fluid to be monitored continuously. Since its conception by Ungerstedt and Pycock in the 1970s [1] and its introduction into clinical practice approximately 25 years ago [2], it has been applied to study the tissue chemistry of several human organs. Most experience has been acquired in the setting of neurocritical care. In this arena, microdialysis has been applied to patients with several conditions, and in particular traumatic brain injury (TBI) and subarachnoid hemorrhage $(\mathrm{SAH})$. There is no doubt that this technique has increased our understanding of the pathophysiology of these disease processes [3]. Furthermore, microdialysis has evolved into a clinical tool for the management of patients on an individual intention-to-treat basis.

In neurocritical care, microdialysis data is typically collected together with intracranial pressure (ICP) [allowing calculation of cerebral perfusion pressure (CPP)] and brain tissue oxygen tension $\left(\mathrm{PbtO}_{2}\right)$. Microdialysis complements these techniques by providing additional information on substrate delivery and metabolism at the cellular level. It thus provides the most direct means to monitor the fundamental process of "energy failure". Of critical importance is that such measurements can be made in real time at the bedside.

In 2003, a group of experts met to review the status of microdialysis as a clinical monitor. This culminated in the publication of a consensus statement in 2004 [4] providing guidance on the use of the technique in TBI and SAH patients. More recently, the role of microdialysis has been evaluated by participants of the International Multidisciplinary Consensus Conference on Multimodality Monitoring [5].

In April 2014, an international forum was convened in Cambridge, UK, with the aim of reviewing evidence for the clinical application of microdialysis in neurocritical care and producing a revised and updated consensus statement [4]. Since the original consensus statement, $\sim 680$ articles have been published on microdialysis in neurocritical care. With this increased experience, there was a need to update the 2004 consensus statement. Although there was some overlap between the objectives of this meeting and that of the International Multidisciplinary Consensus Conference on Multimodality Monitoring, i.e. to review the evidence for using microdialysis to guide clinical care, the principal objective of the International Forum in Microdialysis differed in that 
we aimed to combine literature review with expert opinion to produce practical guidance for the use of cerebral microdialysis as a clinical monitor and to help guide future clinical studies utilizing cerebral microdialysis.

\section{Methods}

The senior authors selected specific 'key speakers' to review a particular area of the literature. These individuals were selected based on their experience and contribution to the literature on a particular aspect of microdialysis monitoring. See Appendix 1 in the supplementary material for a list of key speakers and for the topics they each reviewed. The other participants of the meeting were identified through literature review and by correspondence with the key speakers who were able to identify other clinicians and scientists active in using microdialysis in neurocritical care patients. At the meeting, the literature was presented to the whole group followed by discussion to allow consensus generation. After the meeting, the recommendations were circulated to all participants allowing further discussion and revision.

In addition, for the purposes of the consensus statement, we performed a PubMed database search using the term microdialysis plus one of the following terms: 'traumatic brain injury', 'brain injury', 'trauma', 'subarachnoid hemorrhage', 'stroke', 'epilepsy', 'intracerebral hematoma' and 'cost effectiveness'. We restricted our review to using articles published in the English language. Where recommendations are based on published observational data, the relevant references are given although formal grading was not performed. Where references are not provided, the recommendations are based on expert opinion.

\section{Discussion}

Advances since the 2004 consensus statement

Over the past 10 years, there have been significant advances in the clinical utility of microdialysis in neurocritical care. Evidence from large numbers of patients on how brain chemistry relates to clinical outcome means that we can better define pathological thresholds for microdialysis values. In addition, there is increasing evidence of how different therapeutic manoeuvres can improve chemistry. For a summary of the main advances since the 2004 consensus statement, please see Table 1 .

Most attention has been directed at the clinical utility to monitor TBI and SAH patients: see Table 2 for a summary of how brain chemistry relates to different aspects of the care of patients with TBI and SAH. Microdialysis has also been used in other neurological conditions including intracerebral hemorrhage [6], acute ischemic stroke [7-9], hepatic encephalopathy [10] and epilepsy [11, 12]. However, there is insufficient evidence at present to specifically incorporate the application of

Table 1 Summary of advances since the consensus statement by [4]

\begin{tabular}{|c|c|c|}
\hline & 2004 consensus statement [4] & Current consensus statement \\
\hline Microdialysis methodology & $\begin{array}{l}\text { Monitoring of small molecules using } \\
\text { standard } 10-\mathrm{mm} 20-\mathrm{kDa} \text { catheter } \\
\text { Focus on microdialysis metabolites } \\
\text { as a marker of ischemia and cell } \\
\text { damage }\end{array}$ & $\begin{array}{l}\text { Advances in monitoring of large molecules, with experience of } \\
\text { using } 100-\mathrm{kDa} \text { membrane and colloid for perfusate [13-20] } \\
\text { Novel applications of microdialysis for monitoring and } \\
\text { understanding brain pathology following TBI and SAH }\end{array}$ \\
\hline Core data reporting information & Not defined & $\begin{array}{l}\text { Details are given of the essential information required to } \\
\text { interpret and compare microdialysis data }\end{array}$ \\
\hline Reference values & Not defined & $\begin{array}{l}\text { Pathological thresholds defined for glucose, lactate and the LP } \\
\text { ratio }[6,51,53-55,68-73,79,80]\end{array}$ \\
\hline $\begin{array}{l}\text { Tiered approach to } \\
\text { microdialysis metabolites for } \\
\text { clinical application }\end{array}$ & Not defined & $\begin{array}{l}\text { Glucose and LP ratio more clinically useful than glutamate and } \\
\text { glycerol in TBI and SAH patients }\end{array}$ \\
\hline $\begin{array}{l}\text { Guidance for microdialysis- } \\
\text { directed management }\end{array}$ & Not given & $\begin{array}{l}\text { Suggested therapeutic interventions for when glucose is low } \\
(<0.2 \mathrm{mM}) \text { and for when the LP ratio indicates } \\
\text { ischemia } \pm \text { tissue hypoxia }\end{array}$ \\
\hline Monitoring in TBI & $\begin{array}{l}\text { Guidance on catheter placement in } \\
\text { focal or diffuse injury }\end{array}$ & $\begin{array}{l}\text { Guidance on single or multiple catheter placement based on } \\
\text { whether the injury is focal or diffuse and based on the aims of } \\
\text { microdialysis monitoring }\end{array}$ \\
\hline Monitoring in SAH & $\begin{array}{l}\text { Guidance on catheter placement in } \\
\text { the tissue at risk }\end{array}$ & $\begin{array}{l}\text { Two principal indications for microdialysis monitoring are } \\
\text { defined: } \\
\text { 1. As a primary monitoring device in mechanically ventilated } \\
\text { patients } \\
\text { 2. As a monitor of patients with a secondary neurological } \\
\text { deterioration }\end{array}$ \\
\hline
\end{tabular}


Table 2 Summary of the evidence for how brain chemistry relates to different aspects of the management of patients with TBI and SAH

\begin{tabular}{lll}
\hline How microdialysis monitoring can be used in neurocritical care & $\begin{array}{l}\text { Traumatic } \\
\text { brain injury }\end{array}$ & $\begin{array}{l}\text { Subarachnoid } \\
\text { hemorrhage }\end{array}$ \\
\hline Outcome and prognostication & {$[51,53,78]$} & {$[67,79,81]$} \\
Early warning system of secondary insults & {$[26,27]$} & {$[28,29,80,82]$} \\
$\begin{array}{l}\text { Monitoring and treatment of low cerebral glucose; guiding systemic } \\
\text { glucose management and insulin use }\end{array}$ & {$[56,61,62,64,65]$} & {$[56,63,83,84]$} \\
$\begin{array}{l}\text { Monitoring during CPP-augmentation/reduction } \\
\text { Monitoring during neurological wake-up test (tolerating moderate rises in ICP) }\end{array}$ & {$[48,85,86]$} & {$[54,87]$} \\
$\begin{array}{l}\text { Deciding on transfusion thresholds } \\
\text { Evaluating the effect of body temperature on cerebral chemistry }\end{array}$ & {$[90]$} & {$[89]$} \\
Monitoring after decompressive craniectomy & {$[92]$} & {$[91]$} \\
\hline
\end{tabular}

Table 3 A summary of on-going microdialysis research applications

Investigating the concept of lactate as a substrate as opposed to a metabolic by-product in select patients Use of $100-\mathrm{kDa}$ microdialysis membranes to measure larger molecules including cytokines

Use of ${ }^{13} \mathrm{C}$-labelled substrates to interrogate metabolic pathways in more detail, e.g., the fate of glucose metabolism (glycolysis vs. pentose phosphate pathway) and the fate of lactate as a substrate

Monitoring drug penetration across the blood-brain barrier and the effect of drugs on brain chemistry

Clinical use in pediatric practice

Monitoring of the ionic component of the interstitial space

Monitoring of biomarkers

Development of microfluidic based on-line assays that give continuous neurochemical information in real time
$[79,94]$

$[15,16,18,19,95]$

$[94,96,97]$

$[98,99]$

[100-102]

[103]

$[18,19,104-111]$

$[23,24,112]$ microdialysis in these conditions into the consensus statement.

In addition to recent advances as a clinical monitor, microdialysis continues to be a powerful research tool with numerous, varied and several novel applications that provide insight into various aspects of cerebral biology and pathophysiology. For a summary of on-going and future research, see Table 3 . Overall, further research should be directed at the integration of brain chemistry and other clinical monitoring data to better define targets for the individualized goal-directed management of the brain-injured patient.

Advances in microdialysis methodology

The technique of microdialysis is well established. For details on technique and on the factors that affect relative recovery, i.e. how the substance measured in the dialysate is related to the free concentration in the tissue interstitial space, please see supplementary material.

Microdialysis is used clinically to estimate extracellular interstitial concentrations of small molecules, but can also be used to recover much larger molecules such as inflammatory mediators from the interstitial fluid. Instead of the standard 20-kDa nominal molecular weight cut-off membrane, which recovers glucose, pyruvate, lactate, glycerol, glutamate, and other small hydrophilic molecules, a $100-\mathrm{kDa}$ membrane is used to also recover larger molecules including cytokines. The recovery of small molecules does not differ between the two membrane types [13]. Increased experience in using microdialysis for large molecules less than $100 \mathrm{kDa}$ has been achieved in the past 10 years. Importantly, the use of colloid in the perfusate (e.g., albumin or dextran) significantly improves the relative recovery of these large molecules [14-16]. However, in some situations, colloid perfusate can cause net influx of fluid into the catheter potentially dehydrating the interstitial space, and dextrans of molecular weight $40-250 \mathrm{kDa}$ may leak through the microdialysis membrane potentially disturbing the interstitial microenvironment $[14,15,17]$. These problems may be overcome by using higher molecular weight dextrans, such as $500-\mathrm{kDa}$ dextran, as colloid in the perfusate [18-20]. A useful alternative colloid to dextran is human serum albumin (HAS), which has been shown to improve recovery for the majority of cytokines compared to crystalloid perfusate without significantly dehydrating the interstitial space [16].

Most experience of microdialysis in neurocritical care has been obtained with hourly measurements although more frequent sampling is possible [21-25]. Hourly sampling appears sufficient to detect the metabolic changes that can sometimes precede episodes of intracranial hypertension in TBI and symptomatic delayed ischemia in SAH [26-29]. Hence, microdialysis has the potential to be used as an early warning system of secondary insults. However, dynamic changes in brain 
chemistry, for example due to spreading depolarization [21-23] or observed during aneurysm surgery [24, 30], may not be detected with hourly measurements, so there is potentially scope for improved technology with more frequent microdialysis readings in future, which may lead to better warning of adverse events.

\section{Clinical application in intensive care}

The clinical application of microdialysis in neurocritical care has focused on the delivery of glucose and its metabolism via glycolysis to pyruvate, which under oxidative conditions feeds into the tricarboxylic acid (TCA) cycle. Under hypoxic conditions, or if mitochondrial function is compromised, pyruvate is metabolized to lactate. Hence, the LP ratio is used as a marker of aerobic versus "anaerobic" metabolism not requiring oxygen [31, 32]. Glutamate is measured as a marker of hypoxia/ischemia and has been considered as an indicator of excitotoxicity [31-34]. Glycerol is regarded a marker of hypoxia/ischemia and cell membrane breakdown $[32,35$ 37].

\section{Safety profile}

The technique of cerebral microdialysis is safe. Several published series of patients studied with microdialysis, which include non-brain-injured patients, have not reported adverse events related to microdialysis catheter insertion [29, 38-40]. Cerebral microdialysis has a safety profile at least equivalent to that of intra-parenchymal pressure sensors owing to the catheter's greater flexibility and small diameter [41]. In most circumstances when an adverse event occurs, it relates to the insertion technique rather than the catheter itself. Cerebral microdialysis has mostly been used as a tool for observational studies. Further evaluation of microdialysis as a clinical monitor should include assessment of potential harm caused by microdialysis-directed interventions.

\section{Cost-benefit analysis}

No cost effectiveness studies evaluating microdialysis in neurocritical care have been performed. One study compared ICP monitoring alone against multimodal monitoring, which consisted of transcranial Doppler, jugular venous oxygen saturation and/or $\mathrm{PbtO}_{2}$ monitoring but not microdialysis [42]. Albeit a small study, it demonstrated that increased upfront costs due to consumables and equipment was offset by better clinical outcomes, which meant that multimodal monitoring was cost effective. In TBI patients, there are indications that aggressive management, which includes invasive monitoring, improves outcomes and is cost effective [4346]. However, these studies have not examined microdialysis monitoring per se.

Recommendations from the 2014 International Forum on Microdialysis - the 2014 consensus statement

Methodology

- Catheters should be inserted according to local institutional protocols either by twist drill hole, transcranial bolt, or at craniotomy.

- The first hour of microdialysate collected should not be used for clinical monitoring due to unreliable results caused by insertion trauma and the pump flush sequence.

- To monitor glucose, pyruvate, lactate, glycerol and glutamate catheters with a 20 - or $100-\mathrm{kDa}$ cut-off are available (100-kDa catheters are not yet FDA-approved, although they are CE marked for use in Europe).

- A flow rate of $0.3 \mu \mathrm{L} / \mathrm{min}$ with hourly sampling is recommended, which is the flow rate most commonly used in the cerebral microdialysis literature.

- Publication of microdialysis data should include the following information (core data reporting):

- catheter type

- catheter location based on post-insertion imaging

- flow rate

- membrane length

- perfusion fluid composition

- time from ictus to monitoring

Interpretation of cerebral microdialysis

- Microdialysis monitors substrate delivery and metabolism at the cellular level. Chemistry should be interpreted in the context of the clinical condition of the patient and in conjunction with other monitored parameters including ICP, CPP, $\mathrm{PbtO}_{2}$, cerebrovascular pressure reactivity (PRx) and systemic parameters, in order to determine the likely cause of perturbed metabolism. For example, a rise in LP ratio associated with a fall in CPP and loss of cerebrovascular reactivity (i.e., a high PRx) indicates that the likely cause of disordered chemistry is ischemia.

- Microdialysis is a focal technique. The heterogeneity of brain injury means that brain chemistry varies in different regions of the brain. In TBI, peri-lesional brain demonstrates more perturbed chemistry, in particular a higher LP ratio, compared to other areas of brain [47-52]. Therefore, brain chemistry should be 
interpreted according to catheter location in relation to focal injury based on CT/MRI imaging.
- Measuring cerebral glutamate is an option and may be useful in estimating prognosis.

\section{Glucose}

- Glucose is the main substrate for brain metabolism.

- Periods of low glucose $(<0.8 \mathrm{mM})$ are observed in TBI and SAH.

- Low brain glucose is associated with unfavorable outcome [53-57].

- There is also evidence that high brain glucose is associated with unfavorable outcome indicating that there is an optimal range for brain glucose, although, there is currently insufficient data to define this range $[51,58]$.

- Serum glucose concentration and glycemic control influence brain glucose although this relationship may be lost in injured brain [56, 59-65].

- Brain glucose can be reduced rapidly by secondary insults such as spreading depolarization [22, 66].

\section{Lactate/pyruvate ratio}

- A high LP ratio is associated with unfavorable outcome [6, 51, 53, 54, 57, 67-73].

- The LP ratio is a marker of cellular redox status.

- The LP ratio is a quantitative measure (independent of relative recovery).

- An increased LP ratio may result from a failure of oxygen delivery (ischemic hypoxia) or from nonischemic causes (e.g., mitochondrial dysfunction) [74, 75].

- The absolute lactate and pyruvate concentrations should be considered when interpreting a high LP ratio.

- Ischemia and mitochondrial dysfunction are two ends of a spectrum of factors that increase the LP ratio.

- An increase in the LP ratio in the presence of low pyruvate (and low oxygen) indicates ischemia.

- An increase in LP ratio in the presence of normal or high pyruvate (and normal oxygen) indicates mitochondrial dysfunction.

\section{Glutamate}

- Glutamate is an excitatory amino acid and neurotransmitter. Excess levels are thought to be an additional injurious mechanism and may exacerbate injury in TBI and SAH.

- Excess glutamate release is observed in ischemia [8, $31,33,76]$ and seizures [11, 12, 76, 77].

- There is a described association between glutamate levels, clinical course and outcome in TBI and SAH $[29,78]$.

\section{Glycerol}

- Glycerol is a marker of cell membrane breakdown. It is a potential marker of oxidative stress.

- Glycerol has limited specificity; brain glycerol concentrations are influenced by systemic concentrations. Systemic glycerol concentrations reflect a stress response and/or administration of glycerol-containing substances.

- There is no definitive evidence of a relationship between glycerol and outcome.

- Cerebral glycerol is an option as a marker of cerebral injury.

Guidance for use of microdialysis in traumatic brain injury and subarachnoid hemorrhage-catheter location, reference values and interventions

\section{Traumatic brain injury}

- In diffuse TBI, we recommend placing the catheter in the right (non-dominant) frontal lobe.

- In focal TBI, there are different options for catheter placement that depend on whether the goal is to monitor tissue at risk or normal brain, e.g., to guide systemic glucose treatment.

- Where there is a focal lesion, we recommend, if feasible, catheter placement ipsilateral to the lesion and in radiographically normal brain.

- Multiple catheters are an option in focal TBI.

- E.g., placed at craniotomy for a focal lesion into perilesional brain with a contralateral 'bolt' catheter in radiographically normal brain.

- Stereotactic placement is an option but rarely practical.

\section{Subarachnoid hemorrhage}

- There are two principal indications for the insertion of microdialysis in SAH patients:

1. As a primary monitoring device in mechanically ventilated ('poor-grade') patients.

2. As a monitor of patients with a secondary neurological deterioration.

- As a primary monitoring device, we recommend catheter location in the watershed anterior cerebral artery-middle cerebral artery (ACA-MCA) territory (frontal lobe) on the same side as the maximal blood 
load seen on CT or the ruptured aneurysm. If the blood load is symmetrical, we recommend non-dominant frontal lobe placement.

- In patients with a secondary neurological deterioration, catheter location should be guided by local practice to identify tissue at risk (e.g., CT perfusion scanning or trans-cranial Doppler).

- Multiple catheters are an option in SAH.

\section{Reference values and interventions}

- It is currently difficult to define absolute normal or abnormal values based on the literature. Different groups have used different threshold values to relate microdialysate values to outcome. Furthermore, some authors have used a combination of values to relate microdialysis to clinical outcomes.

- The trend is as important or possibly more important than point values or threshold values.

- It is important to distinguish between normal values, which have been reported in the awake and anesthetised brain of patients undergoing surgery for benign intracranial lesions, and values that characterize pathophysiological disturbance of brain chemistry.

- We propose the following pathological thresholds (one or two stages), for microdialysis at $0.3 \mu \mathrm{l} / \mathrm{min}$, based on observational studies that have explored statistical differences in outcomes in relation to thresholds of microdialysate values. Microdialysate values observed beyond these thresholds indicate that the area of brain being monitored is 'at risk'. We propose clinical interventions that may be appropriate in response to disturbed brain chemistry. Further research is needed to elucidate whether these thresholds can be applied to both peri-lesional and to radiographically normal brain and to identify whether interventions directed by these thresholds improve clinical outcomes.

- Glucose: $<0.2$ and $<0.8 \mathrm{mmol} / \mathrm{L}[53-55,73]$.

- If brain glucose is low $(<0.2 \mathrm{mM})$, a trial of increasing serum glucose (by intravenous or enteral administration and/or loosening glycemic control) should be considered. Factors to consider when deciding whether this is an appropriate intervention include baseline serum glucose concentration and whether other parameters indicate cerebral ischemia. If baseline serum glucose concentration is high, further increasing the glucose concentration is likely to increase the risk of both neurological and systemic complications from hyperglycemia. The precise definition of blood sugar thresholds for safety is beyond the scope of this manuscript, but frank hyperglycemia should be avoided. If other parameters, such as the LP ratio and $\mathrm{PbtO}_{2}$, indicate ischemia, interventions directed at improving cerebral perfusion should be considered first-line.

- Lactate: $>4 \mathrm{mmol} / \mathrm{L}[51,73,79,80]$.

- Lactate/pyruvate ratio: $>25$ and $>40[6,51,53,54$, 68-73].

- If the LP ratio indicates ischemia, i.e. an increase in the LP ratio in the presence of low pyruvate, CPP augmentation is a therapeutic option.

- If the LP ratio is increased in the presence of low brain tissue oxygen, interventions that improve oxygen delivery, such as judiciously increasing the cerebral perfusion pressure, increasing $\mathrm{PaCO}_{2}$, increasing inspired concentration of oxygen and/or correcting anemia, should be considered. However, all of these interventions have potential side effects, and the choice of intervention will depend on the preintervention levels of any given variable, and a consideration of the side effects of the intervention. Thus, for example, in patients with significant hypocarbia, an increase in $\mathrm{PaCO}_{2}$ might be the most appropriate intervention, but may be difficult to achieve due to increases in intracranial pressure.

\section{Tiered approach to the clinical value of substances}

- Accumulating evidence since the last consensus statement indicates that the value of the metabolites can now be considered in a tiered fashion (tier 1 being most robust and useful) for their clinical application as follows. This hierarchy is based on the larger volume of observational data linking glucose and LP ratio with outcome compared to glutamate and glycerol and on the greater potential for glucose and LP ratio to direct clinical interventions.

- Tier 1: glucose and LP ratio.

- Tier 2: glutamate.

- Tier 3: glycerol.

\section{Summary and future directions}

Cerebral microdialysis is a reliable and safe technique that is used in the clinical management of neurocritical care patients and in particular those with severe TBI or SAH. In addition, there are several research applications that are important for developing our understanding of brain physiology, pathophysiology and drug development. Since the 2004 consensus document, there have been significant advances in our understanding of how microdialysis can be 
used. There is now evidence from large numbers of patients on how abnormal brain chemistry relates to clinical outcome. The measurement of glucose, lactate and the LP ratio are now considered more useful than glutamate and glycerol. The LP ratio, interpreted in the light of absolute pyruvate concentrations and $\mathrm{PbtO}_{2}$, can be used to differentiate ischemic from non-ischemic causes of energy dysfunction. Importantly, there is increasing evidence of how different therapeutic manoeuvres influence brain chemistry. Microdialysis is well placed to help guide the management of patients in an individualized and targeted fashion. For its effective use, microdialysis should be integrated into brain multi-modal monitoring systems and interpreted with knowledge of catheter location and clinical context. Future clinical research should focus on assessing the clinical effectiveness of decision-making based on microdialysis, as part of multi-modality monitoring of acute brain injured patients, and its integration into treatment paradigms in neurocritical care.

Acknowledgments We gratefully acknowledge financial support for participants as follows: P.J.H.-National Institute for Health Research (NIHR) Professorship and the NIHR Biomedical Research Centre, Cambridge; I.J.-Medical Research Council (G1002277 ID 98489); A. H.-Medical Research Council, Royal College of Surgeons of England; K.L.H.C.-NIHR Biomedical Research Centre, Cambridge (Neuroscience Theme; Brain Injury and Repair Theme); M.G.B.-Wellcome Trust Dept Health Healthcare Innovation
Challenge Fund (HICF-0510-080); L. H.-The Swedish Research Council, VINNOVA and Uppsala Berzelii Technology Centre for Neurodiagnostics; S. M.-Fondazione IRCCS Cà Granda Ospedale Maggiore Policlinico; D.K.M.-NIHR Senior Investigator Award to D.K.M., NIHR Cambridge Biomedical Research Centre (Neuroscience Theme), FP7 Program of the European Union; M. O.Swiss National Science Foundation and the Novartis Foundation for Biomedical Research; J.S.-Fondo de Investigación Sanitaria (Instituto de Salud Carlos III) (PI11/00700) co-financed by the European Regional Development; M.S.-NIHR University College London Hospitals Biomedical Research Centre; N. S.-Fondazione IRCCS Cà Granda Ospedale Maggiore Policlinico.

Conflicts of interest M Dialysis, Stockholm, Sweden, provided financial support for the 2014 International Microdialysis Forum although neither honorariums nor speaker fees were received by any of the authors. M Dialysis were neither involved in designing the structure of the meeting nor in selecting the participants. H.M. received a travel grant from $M$ Dialysis to attend the meeting. The other authors have no conflicts of interest in relation to this manuscript. An extended conflict of interest statement for all participants is provided in the supplementary material (see Appendix 2).

Open Access This article is distributed under the terms of the Creative Commons Attribution 4.0 International License (http://creativecommons.org/licenses/by/4.0/), which permits use, duplication, adaptation, distribution, and reproduction in any medium or format, as long as you give appropriate credit to the original author(s) and the source, provide a link to the Creative Commons license, and indicate if changes were made.

\section{References}

1. Ungerstedt U, Pycock C (1974) Functional correlates of dopamine neurotransmission. Bull Schweiz Akad Med Wiss 30:44-55

2. Persson L, Hillered L (1992) Chemical monitoring of neurosurgical intensive care patients using intracerebral microdialysis. J Neurosurg 76:72-80. doi:10.3171/jns.1992.76.1.0072

3. Hillered L, Vespa PM, Hovda DA (2005) Translational neurochemical research in acute human brain injury: the current status and potential future for cerebral microdialysis.

J Neurotrauma 22:3-41. doi: 10.1089/neu.2005.22.3

4. Bellander B-M, Cantais E, Enblad P et al (2004) Consensus meeting on microdialysis in neurointensive care. Intensive Care Med 30:2166-2169. doi:10.1007/s00134-004-2461-8
5. Hutchinson P, O'Phelan K, The Participants in the International Multidisciplinary Consensus Conference on Multimodality Monitoring (2014) International multidisciplinary consensus conference on multimodality monitoring: cerebral metabolism. Neurocrit Care 21:1-11. doi 10.1007/s12028-014-0035-3

6. Nikaina I, Paterakis K, Paraforos G et al (2012) Cerebral perfusion pressure, microdialysis biochemistry, and clinical outcome in patients with spontaneous intracerebral hematomas. J Crit Care 27:83-88. doi: 10.1016/j.jcrc.2011.04.004

7. Berger C, Schäbitz W-R, Georgiadis D et al (2002) Effects of hypothermia on excitatory amino acids and metabolism in stroke patients: a microdialysis study. Stroke

33:519-524. doi:

10.1161/hs0102.100878
8. Dohmen C, Bosche B, Graf R et al (2003) Prediction of malignant course in MCA infarction by PET and microdialysis. Stroke 34:2152-2158. doi:10.1161/01.STR.0000083624. 74929.32

9. Schneweis S, Grond M, Staub F et al (2001) Predictive value of neurochemical monitoring in large middle cerebral artery infarction. Stroke 32:1863-1867. doi: 10.1161/01.str.32.8.1863

10. Tofteng F, Jorgensen L, Hansen BA et al (2002) Cerebral microdialysis in patients with fulminant hepatic failure. Hepatology 36:1333-1340. doi: 10.1002/hep.1840360607

11. During MJ, Spencer DD (1993) Extracellular hippocampal glutamate and spontaneous seizure in the conscious human brain. Lancet 341:1607-1610. doi: 10.1016/0140-6736(93)90754-5 
12. Ronne-Engström E, Hillered L, Flink $R$ et al (1992) Intracerebral microdialysis of extracellular amino acids in the human epileptic focus. J Cereb Blood Flow Metab 12:873-876. doi: $10.1038 / \mathrm{jcbfm} .1992 .119$

13. Hutchinson PJ, O'Connell MT, Nortje $\mathrm{J}$ et al (2005) Cerebral microdialysis methodology - evaluation of $20 \mathrm{kDa}$ and $100 \mathrm{kDa}$ catheters. Physiol Meas 26:423-428. doi: 10.1088/0967-3334/26/4/008

14. Hillman J, Aneman O, Anderson $\mathrm{C}$ et al (2005) A Microdialysis technique for routine measurement of macromolecules in the injured human brain. Neurosurgery 56:1264-1270. doi:10.1227/01.NEU.0000159711. 93592.8D

15. Helmy A, Carpenter KLH, Skepper JN et al (2009) Microdialysis of cytokines: methodological considerations, scanning electron microscopy, and determination of relative recovery. J Neurotrauma 26:549-561. doi: 10.1089/neu.2008.0719

16. Helmy A, Carpenter KLH, Menon DK et al (2011) The cytokine response to human traumatic brain injury: temporal profiles and evidence for cerebral parenchymal production. J Cereb Blood Flow Metab 31:658-670. doi: $10.1038 / \mathrm{jcbfm} .2010 .142$

17. Chu J, Koudriavtsev V, Hjort K, Dahlin AP (2014) Fluorescence imaging of macromolecule transport in high molecular weight cut-off microdialysis. Anal Bioanal Chem 406:7601-7609. doi: 10.1007/s00216-014-8192-y

18. Dahlin AP, Wetterhall M, Caldwell KD et al (2010) Methodological aspects on microdialysis protein sampling and quantification in biological fluids: an in vitro study on human ventricular CSF. Anal Chem 82:4376-4385. doi: 10.1021/ac1007706

19. Dahlin AP, Purins K, Clausen F et al (2014) Refined microdialysis method for protein biomarker sampling in acute brain injury in the neurointensive care setting. Anal Chem 86:8671-8679. doi: $10.1021 / \mathrm{ac} 501880 \mathrm{u}$

20. Hillered L, Dahlin AP, Clausen F et al (2014) Cerebral microdialysis for protein biomarker monitoring in the neurointensive care setting - a technical approach. Front Neurol 5:245. doi:10.3389/fneur.2014.00245
21. Sakowitz OW, Santos E, Nagel A et al (2013) Clusters of spreading depolarizations are associated with disturbed cerebral metabolism in patients with aneurysmal subarachnoid hemorrhage. Stroke 44:220-223. doi: 10.1161/STROKEAHA.112.672352

22. Feuerstein D, Manning A, Hashemi $P$ et al (2010) Dynamic metabolic response to multiple spreading depolarizations in patients with acute brain injury: an online microdialysis study. J Cereb Blood Flow Metab 30:1343-1355. doi: 10.1038/jcbfm.2010.17

23. Rogers ML, Feuerstein D, Leong CL et al (2013) Continuous online microdialysis using microfluidic sensors: dynamic neurometabolic changes during spreading depolarization. ACS Chem Neurosci 4:799-807. doi:10.1021/cn400047x

24. Bhatia R, Hashemi P, Razzaq A et al (2006) Application of rapid-sampling, online microdialysis to the monitoring of brain metabolism during aneurysm surgery. Neurosurgery 58:ONS313-20. doi:10.1227/01.NEU.00002 08963.42378.83 (discussion ONS321)

25. Skoglund K, Hillered L, Purins K, Tsitsopoulos PP (2014) The neurological wake-up test does not alter cerebral energy metabolism and oxygenation in patients with severe traumatic brain injury. Neurocrit Care. doi:10.1007/s12028-013-9876-4

26. Adamides AA, Rosenfeldt FL, Winter CD et al (2009) Brain tissue lactate elevations predict episodes of intracranial hypertension in patients with traumatic brain injury. J Am Coll Surg 209:531-539. doi: 10.1016/j.jamcollsurg.2009.05.028

27. Belli A, Sen J, Petzold A et al (2008) Metabolic failure precedes intracranial pressure rises in traumatic brain injury: a microdialysis study. Acta Neurochir (Wien) 150:461-470. doi: 10.1007/s00701-008-1580-3

28. Skjøth-Rasmussen J, Schulz M, Kristensen SR, Bjerre P (2004) Delayed neurological deficits detected by an ischemic pattern in the extracellular cerebral metabolites in patients with aneurysmal subarachnoid hemorrhage. J Neurosurg 100:8-15. doi:10.3171/jns.2004.100.1.0008

29. Sarrafzadeh AS, Sakowitz OW, Kiening KL et al (2002) Bedside microdialysis: a tool to monitor cerebral metabolism in subarachnoid hemorrhage patients? Crit Care Med 30:1062-1070. doi: 10.1097/00003246-200205000-00018
30. Kett-White R, Hutchinson PJ, AlRawi PG et al (2002) Cerebral oxygen and microdialysis monitoring during aneurysm surgery: effects of blood pressure, cerebrospinal fluid drainage, and temporary clipping on infarction. J Neurosurg 96:1013-1019. doi: 10.3171/jns.2002.96.6.1013

31. Hlatky R, Valadka AB, Goodman JC et al (2004) Patterns of energy substrates during ischemia measured in the brain by microdialysis. J Neurotrauma 21:894-906. doi: 10.1089/0897715041526195

32. Tisdall MM, Smith M (2006) Cerebral microdialysis: research technique or clinical tool. Br J Anaesth 97:18-25. doi:10.1093/bja/ael109

33. Enblad P, Valtysson J, Andersson J et al (1996) Simultaneous intracerebral microdialysis and positron emission tomography in the detection of ischemia in patients with subarachnoid hemorrhage. J Cereb Blood Flow Metab 16:637-644. doi: 10.1097/00004647-199607000-00014

34. Hutchinson PJ, Gupta AK, Fryer TF et al (2002) Correlation between cerebral blood flow, substrate delivery, and metabolism in head injury: a combined microdialysis and triple oxygen positron emission tomography study. J Cereb Blood Flow Metab 22:735-745. doi: 10.1097/00004647-200206000-00012

35. Hillered L, Valtysson J, Enblad P, Persson L (1998) Interstitial glycerol as a marker for membrane phospholipid degradation in the acutely injured human brain. J Neurol Neurosurg Psychiatry 64:486-491

36. Clausen T, Alves OL, Reinert $\mathrm{M}$ et al (2005) Association between elevated brain tissue glycerol levels and poor outcome following severe traumatic brain injury. J Neurosurg 103:233-238. doi: 10.3171/jns.2005.103.2.0233

37. Schulz MK, Wang LP, Tange M, Bjerre P (2000) Cerebral microdialysis monitoring: determination of normal and ischemic cerebral metabolisms in patients with aneurysmal subarachnoid hemorrhage. J Neurosurg 93:808-814. doi:10.3171/jns.2000.93.5.0808

38. Agren-Wilsson A, Roslin M, Eklund A et al (2003) Intracerebral microdialysis and CSF hydrodynamics in idiopathic adult hydrocephalus syndrome. J Neurol Neurosurg Psychiatry 74:217-221 
39. Eide PK, Stanisic M (2010) Cerebral microdialysis and intracranial pressure monitoring in patients with idiopathic normal-pressure hydrocephalus: association with clinical response to extended lumbar drainage and shunt surgery. J Neurosurg 112:414-424. doi:10.3171/2009.5.09122

40. Zauner A, Doppenberg EM, Woodward JJ et al (1997) Continuous monitoring of cerebral substrate delivery and clearance: initial experience in 24 patients with severe acute brain injuries. Neurosurgery 41:1082-1091. doi: 10.1097/00006123-199711000-00011 (discussion 1091-1093)

41. Stuart RM, Schmidt M, Kurtz P et al (2010) Intracranial multimodal monitoring for acute brain injury: a single institution review of current practices. Neurocrit Care 12:188-198. doi:10.1007/s12028-010-9330-9

42. Ibrahim MI, Abdullah M, Naing L et al (2007) Cost effectiveness analysis of using multiple neuromodalities in treating severe traumatic brain injury in a developing country like Malaysia. Asian J Surg 30:261-266. doi: 10.1016/S1015-9584(08)60036-6

43. Patel HC, Menon DK, Tebbs S et al (2002) Specialist neurocritical care and outcome from head injury. Intensive Care Med 28:547-553. doi: 10.1007/s00134-002-1235-4

44. Stein SC, Georgoff P, Meghan S et al (2010) Relationship of aggressive monitoring and treatment to improved outcomes in severe traumatic brain injury. J Neurosurg 112:1105-1112. doi:10.3171/2009.8.JNS09738

45. Whitmore RG, Thawani JP, Grady MS et al (2012) Is aggressive treatment of traumatic brain injury cost-effective? J Neurosurg 116:1106-1113. doi: 10.3171/2012.1.JNS11962

46. Elf K, Nilsson P, Enblad P (2002) Outcome after traumatic brain injury improved by an organized secondary insult program and standardized neurointensive care. Crit Care Med 30:2129

47. Ståhl $\mathrm{N}$, Mellergård $\mathrm{P}$, Hallström $\mathrm{A}$ et al (2001) Intracerebral microdialysis and bedside biochemical analysis in patients with fatal traumatic brain lesions. Acta Anaesthesiol Scand 45:977-985

48. Nordström C, Reinstrup P, Xu W et al (2003) Assessment of the lower limit for cerebral perfusion pressure in severe head injuries by bedside monitoring of regional energy metabolism. Anesthesiology 98:809-814. doi: 10.1097/00000542-200304000-00004
49. Engström M, Polito A, Reinstrup P et al (2005) Intracerebral microdialysis in severe brain trauma: the importance of catheter location. J Neurosurg 102:460-469. doi: 10.3171/jns.2005.102.3.0460

50. Timofeev I, Czosnyka M, Carpenter KLH et al (2011) Interaction between brain chemistry and physiology after traumatic brain injury: impact of autoregulation and microdialysis catheter location. J Neurotrauma 28:849-860. doi: 10.1089/neu.2010.1656

51. Timofeev I, Carpenter KLH, Nortje J et al (2011) Cerebral extracellular chemistry and outcome following traumatic brain injury: a microdialysis study of 223 patients. Brain 134:484-494. doi: 10.1093/brain/awq353

52. Vespa PM, O Phelan K, McArthur D et al (2007) Pericontusional brain tissue exhibits persistent elevation of lactate/pyruvate ratio independent of cerebral perfusion pressure. Crit Care Med 35:1153-1160. doi:10.1097/ 01.CCM.0000259466.66310.4F

53. Stein NR, McArthur DL, Etchepare M, Vespa PM (2012) Early cerebral metabolic crisis after tbi influences outcome despite adequate hemodynamic resuscitation. Neurocrit Care 17:49-57. doi: 10.1007/s12028-012-9708-y

54. Schmidt JM, Ko S-B, Helbok R et al (2011) Cerebral perfusion pressure thresholds for brain tissue hypoxia and metabolic crisis after poor-grade subarachnoid hemorrhage. Stroke 42:1351-1356. doi: 10.1161/STROKEAHA.110.596874

55. Vespa PM, McArthur D, O'Phelan K et al (2003) Persistently low extracellular glucose correlates with poor outcome 6 months after human traumatic brain injury despite a lack of increased lactate: a microdialysis study. J Cereb Blood Flow Metab 23:865-877. doi:

$10.1097 /$ 01.WCB.0000076701.45782.EF

56. Oddo M, Schmidt JM, Carrera E et al (2008) Impact of tight glycemic control on cerebral glucose metabolism after severe brain injury: a microdialysis study. Crit Care Med 36:3233-3238. doi: 10.1097/CCM.0b013e31818f4026

57. Dizdarevic K, Hamdan A, Omerhodzic I, Kominlija-Smajic E (2012) Modified Lund concept versus cerebral perfusion pressure-targeted therapy: a randomised controlled study in patients with secondary brain ischaemia. Clin Neurol Neurosurg 114:142-148. doi: 10.1016/j.clineuro.2011.10.005
58. Cesarini KG, Enblad P, RonneEngström E et al (2002) early cerebral hyperglycolysis after subarachnoid haemorrhage correlates with favourable outcome. Acta Neurochir (Wien) 144:1121-1131. doi: 10.1007/s00701-002-1011-9

59. Schlenk F, Graetz D, Nagel A et al (2008) Insulin-related decrease in cerebral glucose despite normoglycemia in aneurysmal subarachnoid hemorrhage. Crit Care 12:R9. doi:10.1186/cc6776

60. Schmidt JM, Claassen J, Ko S-B et al (2012) Nutritional support and brain tissue glucose metabolism in poorgrade SAH: a retrospective observational study. Crit Care 16:R15. doi:10.1186/cc11160

61. Vespa P, McArthur DL, Stein N et al (2012) Tight glycemic control increases metabolic distress in traumatic brain injury: a randomized controlled within-subjects trial. Crit Care Med 40:1923-1929. doi: 10.1097/CCM.0b013e31824e0fcc

62. Vespa P, Boonyaputthikul R, McArthur DL et al (2006) Intensive insulin therapy reduces microdialysis glucose values without altering glucose utilization or improving the lactate/pyruvate ratio after traumatic brain injury. Crit Care Med 34:850-856. doi: 10.1097/01.CCM.0000201875. $12245.6 \mathrm{~F}$

63. Zetterling M, Hillered L, Enblad P et al (2011) Relation between brain interstitial and systemic glucose concentrations after subarachnoid hemorrhage. J Neurosurg 115:66-74. doi:10.3171/2011.3.JNS10899

64. Magnoni S, Tedesco C, Carbonara M et al (2012) Relationship between systemic glucose and cerebral glucose is preserved in patients with severe traumatic brain injury, but glucose delivery to the brain may become limited when oxidative metabolism is impaired: implications for glycemic control. Crit Care Med 40:1785-1791. doi:10.1097/CCM.0b013e318246bd45

65. Rostami E, Bellander BM (2011) Monitoring of glucose in brain, adipose tissue, and peripheral blood in patients with traumatic brain injury: a microdialysis study. J Diabetes Sci Technol 5:596-604. doi: 10.1177/193229681100500314

66. Parkin M, Hopwood S, Jones DA et al (2005) Dynamic changes in brain glucose and lactate in pericontusional areas of the human cerebral cortex, monitored with rapid sampling on-line microdialysis: relationship with depolarisation-like events. J Cereb Blood Flow Metab 25:402-413. doi: 10.1038/sj.jcbfm.9600051 
67. Sarrafzadeh A, Haux D, Küchler I et al (2004) Poor-grade aneurysmal subarachnoid hemorrhage: relationship of cerebral metabolism to outcome. J Neurosurg 100:400-406. doi:10.3171/jns.2004.100.3.0400

68. Paraforou T, Paterakis K, Fountas K et al (2011) Cerebral perfusion pressure, microdialysis biochemistry and clinical outcome in patients with traumatic brain injury. BMC Res Notes 4:540. doi: 10.1186/1756-0500-4-540

69. Samuelsson C, Hillered L, Enblad P, Ronne-Engström E (2009) Microdialysis patterns in subarachnoid hemorrhage patients with focus on ischemic events and brain interstitial glutamine levels. Acta Neurochir (Wien) 151:437-446. doi: 10.1007/s00701-009-0265-x

70. Marcoux J, McArthur DA, Miller C et al (2008) Persistent metabolic crisis as measured by elevated cerebral microdialysis lactate-pyruvate ratio predicts chronic frontal lobe brain atrophy after traumatic brain injury. Crit Care Med 36:2871-2877. doi: 10.1097/CCM.0b013e318186a4a0

71. Vespa PM, Miller C, McArthur D et al (2007) Nonconvulsive electrographic seizures after traumatic brain injury result in a delayed, prolonged increase in intracranial pressure and metabolic crisis. Crit Care Med 35:2830-2836. doi:10.1097/01.CCM.0000295667. 66853.BC

72. Kett-White R, Hutchinson PJ, AlRawi PG et al (2002) Adverse cerebral events detected after subarachnoid hemorrhage using brain oxygen and microdialysis probes. Neurosurgery 50:1213-1221 (discussion 1221-1222)

73. Reinstrup $\mathrm{P}$, Ståhl N, Mellergård $\mathrm{P}$ et al (2000) Intracerebral microdialysis in clinical practice: baseline values for chemical markers during wakefulness, anesthesia, and neurosurgery. Neurosurgery 47:701-710. doi: 10.1227/00006123-200009000-00035

74. Nielsen TH, Olsen NV, Toft P, Nordström C (2013) Cerebral energy metabolism during mitochondrial dysfunction induced by cyanide in piglets. Acta Anaesthesiol Scand 57:793-801. doi:10.1111/aas.12092

75. Purins K, Enblad P, Wiklund L, Lewén A (2012) Brain tissue oxygenation and cerebral perfusion pressure thresholds of ischemia in a standardized pig brain death model. Neurocrit Care 16:462-469. doi: 10.1007/s12028-012-9675-3
76. Vespa P, Prins M, Ronne-Engström E et al (1998) Increase in extracellular glutamate caused by reduced cerebral perfusion pressure and seizures after human traumatic brain injury: a microdialysis study. J Neurosurg 89:971-982. doi: 10.3171/jns.1998.89.6.0971

77. Kinoshita K, Moriya T, Utagawa A et al (2010) Change in brain glucose after enteral nutrition in subarachnoid hemorrhage. J Surg Res 162:221-224. doi:10.1016/j.jss.2009.06.009

78. Chamoun R, Suki D, Gopinath SP et al (2010) Role of extracellular glutamate measured by cerebral microdialysis in severe traumatic brain injury.

J Neurosurg 113:564-570. doi: 10.3171/2009.12.JNS09689

79. Oddo M, Levine JM, Frangos S et al (2012) Brain lactate metabolism in humans with subarachnoid hemorrhage. Stroke 43:1418-1421. doi:10.1161/STROKEAH A.111.648568

80. Unterberg AW, Sakowitz OW, Sarrafzadeh AS et al (2001) Role of bedside microdialysis in the diagnosis of cerebral vasospasm following aneurysmal subarachnoid hemorrhage. J Neurosurg 94:740-749. doi: 10.3171/jns.2001.94.5.0740

81. Nagel A, Graetz D, Schink T et al (2009) Relevance of intracranial hypertension for cerebral metabolism in aneurysmal subarachnoid hemorrhage. J Neurosurg 111:94-101. doi:10.3171/2009.1.JNS08587

82. Nilsson OG, Brandt L, Ungerstedt U, Säveland H (1999) Bedside detection of brain ischemia using intracerebral microdialysis: subarachnoid hemorrhage and delayed ischemic deterioration. Neurosurgery 45:1176-1184 (discussion 1184-1185)

83. Schlenk F, Nagel A, Graetz D, Sarrafzadeh AS (2008) Hyperglycemia and cerebral glucose in aneurysmal subarachnoid hemorrhage. Intensive Care Med 34:1200-1207. doi: 10.1007/s00134-008-1044-5

84. Helbok R, Schmidt JM, Kurtz P et al (2010) Systemic glucose and brain energy metabolism after subarachnoid hemorrhage. Neurocrit Care 12:317-323. doi: 10.1007/s 12028-009-9327-4

85. Johnston AJ, Steiner LA, Coles JP et al (2005) Effect of cerebral perfusion pressure augmentation on regional oxygenation and metabolism after head injury. Crit Care Med 33:189-195. doi:10.1097/01. CCM.0000149837.09225.BD
86. Johnston AJ, Steiner LA, Chatfield DA et al (2004) Effect of cerebral perfusion pressure augmentation with dopamine and norepinephrine on global and focal brain oxygenation after traumatic brain injury. Intensive Care Med 30:791-797. doi: 10.1007/s00134-003-2155-7

87. Chen HI, Stiefel MF, Oddo $M$ et al (2011) Detection of cerebral compromise with multimodality monitoring in patients with subarachnoid hemorrhage. Neurosurgery 69:53-63. doi: 10.1227/NEU.0b013e3182191451 (discussion 63)

88. Helbok R, Kurtz P, Schmidt MJ et al (2012) Effects of the neurological wake-up test on clinical examination, intracranial pressure, brain metabolism and brain tissue oxygenation in severely brain-injured patients. Crit Care 16:R226. doi:10.1186/cc11880

89. Oddo M, Milby A, Chen I et al (2009) Hemoglobin concentration and cerebral metabolism in patients with aneurysmal subarachnoid hemorrhage. Stroke 40:1275-1281. doi: 10.1161/STROKEAHA.108.527911

90. Soukup J, Zauner A, Doppenberg EMR et al (2002) Relationship between brain temperature, brain chemistry and oxygen delivery after severe human head injury: the effect of mild hypothermia. Neurol Res 24:161-168. doi: 10.1179/016164102101199710

91. Oddo M, Frangos S, Milby A et al (2009) Induced normothermia attenuates cerebral metabolic distress in patients with aneurysmal subarachnoid hemorrhage and refractory fever. Stroke 40:1913-1916. doi: 10.1161/STROKEAHA.108.534115

92. Ho CL, Wang CM, Lee KK et al (2008) Cerebral oxygenation, vascular reactivity, and neurochemistry following decompressive craniectomy for severe traumatic brain injury. J Neurosurg 108:943-949. doi: 10.3171/JNS/2008/108/5/0943

93. Nagel A, Graetz D, Vajkoczy P, Sarrafzadeh AS (2009) Decompressive craniectomy in aneurysmal subarachnoid hemorrhage: relation to cerebral perfusion pressure and metabolism. Neurocrit Care 11:384-394. doi: 10.1007/s12028-009-9269-x

94. Gallagher CN, Carpenter KLH, Grice $P$ et al (2009) The human brain utilizes lactate via the tricarboxylic acid cycle: a 13C-labelled microdialysis and highresolution nuclear magnetic resonance study. Brain 132:2839-2849. doi: 10.1093/brain/awp202 
95. Hillman J, Milos P, Yu ZQ et al (2006) Intracerebral microdialysis in neurosurgical intensive care patients utilising catheters with different molecular cut-off (20 and $100 \mathrm{kD}$ ). Acta Neurochir (Wien) 148:319-324. doi:10.1007/s00701-005-0670-8

96. Carpenter KLH, Jalloh I, Gallagher $\mathrm{CN}$ et al (2014) (13)C-labelled microdialysis studies of cerebral metabolism in TBI patients. Eur $\mathbf{J}$ Pharm Sci 57:87-97. doi: 10.1016/j.ejps.2013.12.012

97. Jalloh I, Carpenter KLH, Grice P et al (2015) Glycolysis and the pentose phosphate pathway after human traumatic brain injury: microdialysis studies using 1,2-(13)C2 glucose. J Cereb Blood Flow Metab 35:111-120. doi: 10.1038/jcbfm.2014.177

98. Notkina N, Dahyot-Fizelier C, Gupta AK (2012) In vivo microdialysis in pharmacological studies of antibacterial agents in the brain. $\mathrm{Br} \mathrm{J}$ Anaesth 109:155-160. doi: 10.1093/bja/aes216

99. Dahyot-Fizelier C, Timofeev I, Marchand S et al (2010) Brain microdialysis study of meropenem in two patients with acute brain injury. Antimicrob Agents Chemother 54:3502-3504. doi: 10.1128/AAC.01725-09

100. Charalambides C, Sgouros S, Sakas D (2010) Intracerebral microdialysis in children. Childs Nerv Syst 26:215-220. doi: 10.1007/s00381-009-1031-3

101. Richards DA, Tolias CM, Sgouros S, Bowery NG (2003) Extracellular glutamine to glutamate ratio may predict outcome in the injured brain: a clinical microdialysis study in children. Pharmacol Res 48:101-109. doi:10.1016/s1043-6618(03)00081-1
102. Tolias CM, Richards DA, Bowery NG, Sgouros S (2002) Extracellular glutamate in the brains of children with severe head injuries: a pilot microdialysis study. Childs Nerv Syst 18:368-374. doi: 10.1007/s00381-002-0623-y

103. McNay EC, Sherwin RS (2004) From artificial cerebro-spinal fluid (aCSF) to artificial extracellular fluid (aECF): microdialysis perfusate composition effects on in vivo brain ECF glucose measurements. J Neurosci Methods 132:35-43. doi: 10.1016/j.jneumeth.2003.08.014

104. Marklund N, Blennow K, Zetterberg H et al (2009) Monitoring of brain interstitial total tau and beta amyloid proteins by microdialysis in patients with traumatic brain injury. J Neurosurg 110:1227-1237. doi: 10.3171/2008.9.JNS08584

105. Clausen F, Marklund N, Lewén A et al (2012) Interstitial F(2)-isoprostane 8 -iso-PGF $(2 \alpha)$ as a biomarker of oxidative stress after severe human traumatic brain injury. J Neurotrauma 29:766-775. doi: 10.1089/neu.2011.1754

106. Sen J, Smith M, Belli A et al (2005) Extracellular fluid S100B in the injured brain: a future surrogate marker of acute brain injury? Acta Neurochir (Wien) 147:897-900. doi: 10.1007/s00701-005-0526-2

107. Magnoni S, Esparza TJ, Conte V et al (2012) Tau elevations in the brain extracellular space correlate with reduced amyloid- $\beta$ levels and predict adverse clinical outcomes after severe traumatic brain injury. Brain 135:1268-1280. doi: 10.1093/brain/awr286
108. Helbok R, Schiefecker A, Delazer M et al (2014) Cerebral tau is elevated after aneurysmal subarachnoid haemorrhage and associated with brain metabolic distress and poor functional and cognitive long-term outcome. J Neurol Neurosurg Psychiatry. doi: 10.1136/jnnp-2013-307326

109. Antunes AP, Schiefecker AJ, Beer R et al (2014) Higher brain extracellular potassium is associated with brain metabolic distress and poor outcome after aneurysmal subarachnoid hemorrhage. Crit Care 18:R119. doi: 10.1186/cc13916

110. Brody DL, Magnoni S, Schwetye KE et al (2008) Amyloid-beta dynamics correlate with neurological status in the injured human brain. Science 321:1221-1224. doi: 10.1126/science. 1161591

111. Petzold A, Tisdall MM, Girbes AR et al (2011) In vivo monitoring of neuronal loss in traumatic brain injury: a microdialysis study. Brain 134:464-483. doi: 10.1093/brain/awq360

112. Parkin MC, Hopwood SE, Boutelle MG, Strong AJ (2003) Resolving dynamic changes in brain metabolism using biosensors and on-line microdialysis. Trends Anal Chem 22:487-497. doi: 10.1016/S0165-9936(03)00912-9 